\title{
The effect of non-invasively obtained central blood pressure on cardiovascular outcome in diabetic patients in Assiut University Hospitals
}

\author{
Lobna F. El Toony, Andrew N. Ramzy* and Mohamed A. A. Abozaid
}

\begin{abstract}
Background: The major cause of morbidity and mortality in diabetes is cardiovascular disease, which is exacerbated by the presence of hypertension. Therefore, proper control of BP in diabetic hypertensive patients is essential. Few studies have specifically investigated the prognostic significance of central BP in Egyptian populations with diabetes and hypertension and its relation with cardiovascular outcome. This study aims to evaluate relation between central BP and diabetic composite cardiovascular complications.

Results: Diabetic patients with CVD were significantly older ( $p$ value $<0.01$ ), obese ( $p$ value $<0.01$ ) with long duration of diabetes ( $p$ value $<0.001$ ) and had significantly higher peripheral and central systolic and diastolic BP and higher Alx@75 ( $p$ values $<0.01$ ) than those without CVD. Regarding the metabolic parameters, they had significantly higher fasting blood glucose, HbA1c, and higher blood cholesterol levels ( $p$ values $<0.001$ ), higher $\mathrm{LDL}$ ( $p$ value $<0.01$ ), triglycerides levels ( $p$ value $=0.014$ ), and microalbuminuria ( $p$ value $=0.028$ ). Logistic regression analysis found increased BMI, central systolic BP, and Alx@75 were independent predictors of composite CVD ( $p$ values $<0.05$ ).

Conclusions: There is a pattern of favorability towards central rather than peripheral BP indices to predict the occurrence of CVD in diabetic patients.
\end{abstract}

Keywords: Type 2 diabetes, Central blood pressure, Composite cardiovascular diseases, Assiut University Hospitals

\section{Background}

Type 2 diabetes accounts for $90-95 \%$ of all diabetes. This form encompasses individuals who have relative (rather than absolute) insulin deficiency and have peripheral insulin resistance [1]. According to IDF Diabetes Atlas 2019, The International Diabetes Federation (IDF) has identified Egypt as the ninth leading country in the world for the number of patients with T2D [2]. T2DM negatively affects the prognosis of patients by markedly increasing both hospitalization and mortality rate

\footnotetext{
*Correspondence: Andrew_tamer@med.aun.edu.eg; Andrew_ nader1993@yahoo.com

Assiut University Hospitals, Internal Medicine Department, Faculty of Medicine, Assiut University, Assiut, Egypt
}

[3]. Beyond the inherent increase in mortality in diabetic subjects, when diabetes mellitus is combined with manifestations of CVD, such as myocardial infarction or stroke, the mortality rate is nearly doubled, leading to an estimated reduction in life expectancy of $\approx 12$ years [4].

In Egypt, the prevalence of HTN has been increasing. Recently, it was estimated to be $29.5 \%$ according to the 2017 WHO STEPwise survey in Egypt [5]. Hypertension and type 2 diabetes are well known to be common comorbidities. Hypertension is twice as frequent in patients with diabetes in comparison with those who do not have diabetes. Moreover, patients with hypertension often experience insulin resistance and are at higher risk of diabetes developing than are normotensive individuals. 
The major cause of morbidity and mortality in diabetes is cardiovascular disease [6], which is exacerbated by hypertension. Accordingly, diabetes and hypertension are closely related because of similar risk factors, such as dysfunction of endothelial cells, vascular inflammation, arterial remodeling, atherosclerosis, dyslipidemia, and obesity. There is also substantial overlap in the cardiovascular complications of diabetes and hypertension related primarily to microvascular and macrovascular disease [7].

Therefore, proper control of blood pressure (BP) in diabetic patients with hypertension is essential. Yet, it is not the BP within the arm (brachial) artery that causes strokes and heart attacks, rather, it is the BP within the central arteries which directly interacting with the brain and the heart. Thus, while cuff BP is measured at a peripheral (brachial) artery, the goal is to estimate the pressure load experienced by the central organs (supplied by the aorta) as the best marker of risk from high BP [8].

A number of methods are now available for assessing central pressure. The most direct method involves cardiac catheterization and recording of the blood pressure in the ascending aorta using a pressure-sensing catheter. However, this is highly invasive, technically demanding, and clearly unsuitable for use in routine screening of large populations. More recently, a number of non-invasive methods have been developed, where pressure waveforms are recorded from sites distal to the aorta, such as the carotid, radial, or brachial arteries, and calibrated to blood pressure recorded by cuff sphygmomanometry. Each of these approaches has their own strengths and limitations [9].

\section{Aim of the work}

$\checkmark$ Detection of the relation between central blood pressure and diabetic cardiovascular complications mainly coronary heart disease.

\section{Methods}

This study conducted in Internal medicine outpatient clinics, Assuit University Hospitals during the period from January 2018 to January 2020.

One hundred patients were included in the study and separated into two groups :

A- 49 patients were known to be diabetic and free from CVD.

B- 51 patients were known to be diabetic and with CVD.

Demographic data such as age, gender, cigarette smoking status, duration of diabetes and hypertension, previous medical history, and current medications usage (anti-hypertensive and anti-diabetic), history of cardiovascular disease were collected using questionnaire.

After that systemic examination was done for all patients including examination of the cardiovascular, chest, abdomen, and nervous systems.

Peripheral BP was measured based on the JNC8 guideline recommendation. Patients sit quietly for $10 \mathrm{~min}$ with their back supporting. Non-dominant arm was placed on the heart level and 3 BP readings were obtained with 1-min interval between each reading, and the last 2 readings were used to calculate the mean brachial BP level [10].

Central BP was measured using device called Mobilo-graph which is a well validated non-invasive device made in Germany $[11,12]$. This device uses a brachial based cuff and based on a transfer function, central pressure curves are obtained and processed. Central systolic and diastolic BP (cSBP/cDBP) and augmentation index adjusted for 75 beats per minute of heart rate (AIx@75), which is considered a reflection of arterial stiffness [13], were derived for analysis.

After central BP measurement, fasting venous blood was drawn for lipid profiles, fasting plasma glucose, glycated hemoglobin, CRP, and serum creatinine level. Urine analysis was done to detect albuminuria.

Written informed consent for publication of their clinical details and/or clinical images was obtained from the patient. A copy of the consent form is available for review by the Editor of this journal.

\section{Inclusion criteria}

- Patients aged 40-60 years old

- Patients in groups A and B are documented to have type $2 \mathrm{DM}$

- Patients in group B are documented to have CVD with either ECG or echocardiography.

- Hypertensive patients enrolled must be compliant on their treatment for at least 1 month

\section{Exclusion criteria}

- Pregnancy or breastfeeding.

- Concomitant therapy of digoxin, lithium, nondepolarizing skeletal muscle relaxants, sex hormone.

- Documented connective tissue diseases such as systemic lupus erythematosus.

\section{Consent for publication}

Informed written consent was obtained from all the participants. 


\section{Statistical analysis}

Statistical analysis was done by IBM SPSS statistics 20 . Results were presented as means \pm standard deviation (SD) for quantitative data and as numbers with percentages for qualitative data. Statistical associations between quantitative data were determined using oneway ANOVA test with Tukey HSD test and Student's $t$ test. The chi-square test was used for qualitative data. To evaluate the relation between central blood pressure and diabetic hypertensive composite CVD, variables being significantly correlated with composite CVD in univariate analysis will be entered in a multivariate model using stepwise logistic regression. A $P$ value $<0.05$ was considered statistically significant, $<0.01$ highly significant, and $<0.001$ very highly significant.

\section{Results}

Among the hundred diabetic patients, there were 51 patients with composite CVD. They had been compared with the other patients without composite CVD to evaluate the association between central blood pressure and diabetic with composite CVD.

It was found that increasing age, BMI together with increasing duration of diabetes were statistically highly significant ( $p$ values $0.009,0.002$, and $<0.001$ respectively) in those with composite cardiovascular diseases (CVD). Furthermore, both peripheral and central systolic and peripheral and central diastolic blood pressure in addition to Aix@75 were significantly higher in diabetic with CVD than those without CVD ( $p$ values < 0.01 ). Regarding the metabolic parameters, it was found that those with CVD had significantly higher fasting blood glucose, $\mathrm{Hb}$ A1c, total cholesterol levels ( $p$ values $<0.001$ each), LDL ( $p$ value $<0.01$ ), triglycerides levels ( $p$ value 0.014$)$, and microalbuminuria ( $p$ value 0.028 ) (Table 1).

Aspirin and statins were also significantly higher in those with CVD due to their related medical conditions.

Logistic regression analysis was performed to evaluate the independent predictors of the occurrence of composite CVD in diabetic patients showing that increased BMI, central SBP, and Aix 75 were significantly associated with composite CVD ( $p$ values < 0.05) (Table 2).

\section{Discussion}

Up to our knowledge, few studies have specifically investigated the prognostic significance of central BP among Egyptian populations with diabetes and hypertension. This study found that although there was no significant difference between central DBP and peripheral DBP in all studied cases, peripheral SBP was significantly higher than central SBP in each of the studied groups $(p$ values $<0.001)$. This phenomenon of systolic pressure amplification arises principally due to an increase in the stiffness of the arterial walls moving away from the heart. As the pressure wave travels from the highly elastic central arteries to the stiffer brachial artery, the upper portion of the wave becomes narrower, the systolic peak becomes more prominent, and systolic pressure increases. Patients with type 2 diabetes (T2D) have vascular irregularities that affect blood pressure (BP) amplification and the indices of central BP [14].

In the present study, comparing between patients with composite CVD in our study and those without composite CVD, there was statistically significant difference between both groups as regards peripheral SBP, mean peripheral BP, and central SBP ( $p$ values $<0.001$ each) (higher in those with composite CVD group), and there were high significant differences between the two groups in peripheral DBP, central DBP, and Aix 75 ( $p$ value < 0.01 each) (higher in those with composite CVD group). This goes in run with another study which revealed statistically significant difference between both groups as regards peripheral SBP and DBP, central SBP and DBP in addition to Aix 75 with $(P$ value $<0.05)$ [15].

As regards metabolic parameters of the studied diabetic groups, there was statistically significant difference between patients with CVD and those without CVD as regards fasting blood glucose, $\mathrm{Hb} \mathrm{A} 1 \mathrm{c}$, total cholesterol levels ( $p$ values $<0.001$ each), LDL $(p$ value $<0.01)$, triglycerides levels ( $p$ value 0.014 ) and microalbuminurisa ( $p$ value 0.028$)$. This results were also evident in Yeung et al. study where HbA1c was related to CAD [16] and Silbernagel et al. where there was a continuous positive association between LDL and triglycerides and cardiovascular mortality [17].

Logistic regression analysis displaying independent predictors of the occurrence of composite CVD in diabetic patients which showed that increased BMI, central SBP, and Aix 75 were significantly associated with composite CVD ( $p$ values $<0.05$ ).

By using the heart-rate-corrected augmentation index (Aix75) and aortic pulse wave velocity (PWV), arterial stiffness, an important mechanical property of the arterial system, can be evaluated. Elevated stiffness increases the development of cardiovascular complications in hypertensive patients and normal individuals [13]. Data were analyzed from 11 longitudinal studies involving 5648 subjects followed for an average of 45 months. After correcting for $\mathrm{CV}$ risk factors that included brachial BP or history of hypertension in five studies, an absolute increase of $10 \%$ in central augmentation index corresponded to 31.8 and $38.4 \%$ relative risk increase for $\mathrm{CV}$ and all-cause mortality, respectively [18]. 
Table 1 Characteristics of diabetic with composite CVD and without composite CVD groups

\begin{tabular}{|c|c|c|c|}
\hline & $\begin{array}{l}\text { With composite CVD } \\
n=51\end{array}$ & $\begin{array}{l}\text { Without composite CVD } \\
n=49\end{array}$ & $P$ values \\
\hline \multicolumn{4}{|l|}{ Gender no. (\%) } \\
\hline Male & $15(29.4 \%)$ & 18(36.7\%) & 0.436 \\
\hline Female & $36(70.6 \%)$ & $31(63.3 \%)$ & \\
\hline $\begin{array}{l}\text { Age } \\
\text { Mean } \pm \text { SD }\end{array}$ & $54.78 \pm 5.03$ & $52.12 \pm 4.96$ & 0.009 \\
\hline $\begin{array}{l}\text { BMI } \\
\text { Mean } \pm \text { SD }\end{array}$ & $33.14 \pm 7.79$ & $28.82 \pm 5.37$ & 0.002 \\
\hline $\begin{array}{l}\text { Smoking } \\
\text { no. (\%) }\end{array}$ & $10(19.6 \%)$ & $9(18.4 \%)$ & 0.874 \\
\hline $\begin{array}{l}\text { HTN } \\
\text { No. (\%) }\end{array}$ & $28(54.9 \%)$ & $22(44.9 \%)$ & 0.317 \\
\hline $\begin{array}{l}\text { Diabetic duration } \\
\text { Mean } \pm \text { SD }\end{array}$ & $11.15 \pm 6.54$ & $6.54 \pm 3.4$ & 0.000 \\
\hline Peripheral SBP & $137.12 \pm 16.68$ & $121.24 \pm 13.91$ & 0.000 \\
\hline Peripheral DBP & $82.18 \pm 13.25$ & $76.33 \pm 11.35$ & 0.02 \\
\hline Mean peripheral $\mathrm{BP}$ & $100.78 \pm 12.85$ & $90.96 \pm 10.59$ & 0.000 \\
\hline Central SBP & $126.78 \pm 16.26$ & $112.73 \pm 11.63$ & 0.000 \\
\hline Central DBP & $83.41 \pm 13.45$ & $76.96 \pm 11.35$ & 0.011 \\
\hline Aix 75 & $26.67 \pm 11.57$ & $20.57 \pm 12.04$ & 0.011 \\
\hline FBS (mg/dl) & $295.88 \pm 84.73$ & $172.37 \pm 77.19$ & 0.000 \\
\hline HbA1c (\%) & $9.86 \pm 1.71$ & $6.92 \pm 1.34$ & 0.000 \\
\hline Creatinine (umol/L) & $94.9 \pm 57.08$ & $88.18 \pm 41.61$ & 0.504 \\
\hline LDL (mg/dl) & $144.37 \pm 62.81$ & $113.73 \pm 28.72$ & 0.002 \\
\hline TG (mg/dl) & $209.22 \pm 77.99$ & $165.08 \pm 98.36$ & 0.014 \\
\hline Cholesterol (mg/dl) & $206.65 \pm 59.31$ & $164.47 \pm 47.94$ & 0.000 \\
\hline $\begin{array}{l}\text { Microalbuminuria } \\
\text { no. (\%) }\end{array}$ & $14(27.5 \%)$ & $5(10.2 \%)$ & 0.028 \\
\hline \multicolumn{4}{|c|}{$\begin{array}{l}\text { Anti-diabetic medication } \\
\text { no. (\%) }\end{array}$} \\
\hline Insulin & $23(45.1 \%)$ & 18(36.7\%) & 0.395 \\
\hline Sulfonylurea & 20(39.2\%) & $21(42.9 \%)$ & 0.711 \\
\hline Metformin & $11(21.6 \%)$ & $12(24.5 \%)$ & 0.729 \\
\hline DPP4I & $5(9.8 \%)$ & $2(4.1 \%)$ & 0.437 \\
\hline SGLT2I & $0(0 \%)$ & $3(6.1 \%)$ & 0.114 \\
\hline \multicolumn{4}{|l|}{$\begin{array}{l}\text { HTN medication } \\
\text { no. }(\%)\end{array}$} \\
\hline B-blocker & $15(29.4 \%)$ & $5(10.2 \%)$ & 0.016 \\
\hline Diuretics & $6(11.8 \%)$ & $5(10.2 \%)$ & 0.803 \\
\hline ACEI & $6(11.8 \%)$ & $11(22.4 \%)$ & 0.155 \\
\hline ARBs & $6(11.8 \%)$ & $3(6.1 \%)$ & 0.488 \\
\hline CCB & $4(7.8 \%)$ & $4(8.2 \%)$ & 1 \\
\hline \multicolumn{4}{|l|}{$\begin{array}{l}\text { Other medication } \\
\text { no. }(\%)\end{array}$} \\
\hline Aspirin & $26(51 \%)$ & $1(2 \%)$ & 0.000 \\
\hline Statin & $9(17.6 \%)$ & $1(2 \%)$ & 0.016 \\
\hline
\end{tabular}

Another study observed a strong association between cardiovascular outcomes and central, rather than brachial pressure [19]. In contrast, in the Framingham
Heart Study Mitchell et al. show no additional value of carotid blood pressure [20].

The brain, the heart affected by central blood pressure more directly than peripheral, brachial blood 
Table 2 Logistic regression analysis displaying independent predictors of the occurrence of composite CVD in diabetic patients

\begin{tabular}{|c|c|c|c|c|c|c|c|}
\hline & \multirow[t]{2}{*}{$B$} & \multirow[t]{2}{*}{ S.E. } & \multirow[t]{2}{*}{ Wald } & \multirow[t]{2}{*}{ Sig. } & \multirow[t]{2}{*}{$\operatorname{Exp}(B)$} & \multicolumn{2}{|c|}{ 95\% C.I. for EXP(B) } \\
\hline & & & & & & Lower & Upper \\
\hline Age & 0.102 & 0.094 & 1.183 & 0.277 & 1.107 & 0.921 & 1.331 \\
\hline BMI & 0.179 & 0.089 & 4.035 & 0.045 & 1.197 & 1.004 & 1.426 \\
\hline Diabetic duration & 0.071 & 0.105 & 0.456 & 0.500 & 1.073 & 0.874 & 1.317 \\
\hline Central systolic Bp & 0.135 & 0.059 & 5.122 & 0.024 & 1.144 & 1.018 & 1.286 \\
\hline Augmentation index75 & 0.116 & 0.054 & 4.656 & 0.031 & 1.123 & 1.011 & 1.247 \\
\hline Fasting blood sugar FBS & 0.010 & 0.006 & 2.509 & 0.113 & 1.010 & 0.998 & 1.022 \\
\hline LDL & 0.012 & 0.013 & 0.877 & 0.349 & 1.012 & 0.987 & 1.038 \\
\hline $\mathrm{HDL}$ & 0.076 & 0.052 & 2.168 & 0.141 & 1.079 & 0.975 & 1.195 \\
\hline TG & $-0.001-$ & 0.008 & 0.033 & 0.856 & 0.999 & 0.984 & 1.014 \\
\hline Aspirin(1) & 5.460 & 2.342 & 5.437 & 0.020 & 235.112 & 2.388 & 23145.827 \\
\hline Statin(1) & $-1.318-$ & 2.333 & 0.319 & 0.572 & 0.268 & 0.003 & 25.888 \\
\hline Microalbuminuria(1) & $-.440-$ & 1.468 & 0.090 & 0.764 & 0.644 & 0.036 & 11.435 \\
\hline B blocker(1) & 1.122 & 1.056 & 1.128 & 0.288 & 3.070 & 0.387 & 24.336 \\
\hline Constant & $-38.741-$ & 11.656 & 11.047 & 0.001 & 0.000 & & \\
\hline
\end{tabular}

pressure. Thus, central blood pressure is more accurate and direct reflection of the pathophysiological outcomes of elevated blood pressure on the brain than peripheral blood pressure [21].

\section{Recommendations}

- Raising the awareness among health care providers of the importance of measuring central arterial blood pressure using the newer non-invasive devices and considering it as a guide of therapy to prevent composite cardiovascular complications of type 2 DM.

- More studies are needed with a large sample size aiming to assess the effect of anti-hypertensive and anti-diabetic drug classes on central arterial blood pressure.

\section{Conclusions}

This work clearly identified a pattern of favorability towards central BP indices being better than brachial BP in terms of their ability to predict the occurrence of composite cardiovascular diseases in diabetic patients.

\section{Abbreviations}

Alx@75: Augmentation index adjusted for 75 beats per minute of heart rate; BP: Blood pressure; CSBP/CDBP: Central systolic and diastolic BP; CVD: Cardiovascular diseases; DBP: Diastolic blood pressure; SBP: Systolic blood pressure; CBP: Central blood pressure; PBP: Peripheral blood pressure; DM: Diabetes mellitus.

\section{Acknowledgements}

Not applicable.

\section{Authors' contributions}

LFT, ANR, and MAA conceived and designed the research. LFT, ANR, and MAA recruited patients, carried out the clinical investigations, and collected patients' clinical data. ANR performed the experiment. LFT, ANR, and MAA prepared the original draft of the manuscript, participated in data analysis and writing, and read and agreed to the published version of the manuscript. The authors read and approved the final manuscript.

\section{Funding}

$\mathrm{Nil}$

Availability of data and materials

The datasets used and/or analyzed during the current study are available on reasonable request.

\section{Declarations}

\section{Ethics approval and consent to participate}

There was no risk during the application of the research. Privacy and confidentiality was maintained during all stages of assessment. Every patient subjected to this study was informed about the results of the research. The work is approved by Ethical Committee of Faculty of Medicine of Assiut University on 11 April 2018 (approval number 17100490). Informed written consent was obtained from all the participants in this study. Refusal would not affect medical services which are usually offered.

\section{Consent for publication}

Not applicable.

\section{Competing interests}

The authors declare that they have no competing interest.

Received: 11 August 2021 Accepted: 16 December 2021

Published online: 14 January 2022

\section{References}

1. Association, A.D. (2020) 2. Classification and diagnosis of diabetes: standards of medical care in diabetes-2020. Diabetes Care 43(Suppl 1):S14

2. Saeedi $\mathrm{P}$ et al (2019) Global and regional diabetes prevalence estimates for 2019 and projections for 2030 and 2045: Results from the 
International Diabetes Federation Diabetes Atlas. Diabetes Res Clin Pract 157:107843

3. Chatterjee $S$ et al (2018) Diabetes structured self-management education programmes: a narrative review and current innovations. Lancet Diabetes Endocrinol 6(2):130-142

4. Pennells L et al (2019) Equalization of four cardiovascular risk algorithms after systematic recalibration: individual-participant meta-analysis of 86 prospective studies. Eur Heart J 40(7):621-631

5. El Faramawy A et al (2020) Registry of the Egyptian specialized hypertension clinics: patient risk profiles and geographical differences. J Hum Hypertens 34(7):520-527

6. Miller RG, Costacou T, Orchard TJ (2019) Risk factor modeling for cardiovascular disease in type 1 diabetes in the pittsburgh epidemiology of diabetes complications (EDC) study: a comparison with the diabetes control and complications trial/epidemiology of diabetes interventions and complications study (DCCT/EDIC). Diabetes 68(2):409-419

7. Petrie JR, GuzikTJ, Touyz RM (2018) Diabetes, hypertension, and cardiovascular disease: clinical insights and vascular mechanisms. Can J Cardiol 34(5):575-584

8. McEniery CM et al (2014) Central blood pressure: current evidence and clinical importance. Eur Heart J 35(26):1719-1725

9. Cheng HM et al (2020) Central blood pressure for the management of hypertension: is it a practical clinical tool in current practice? J Clin Hypertens 22(3):391-406

10. Mahdavi M et al (2020) Insight into blood pressure targets for universal coverage of hypertension services in Iran: the 2017 ACC/AHA versus JNC 8 hypertension guidelines. BMC Public Health 20(1):1-9

11. Sánchez R, Pessana F, Lev G et al. (2020) Central Blood Pressure Waves Assessment: A Validation Study of Non-invasive Aortic Pressure Measurement in Human Beings. High Blood Press Cardiovasc Prev 27:165-174. https://doi.org/10.1007/s40292-020-00371-4

12. Vaios $V$ et al (2018) Accuracy of a newly-introduced oscillometric device for the estimation of arterial stiffness indices in patients on peritoneal dialysis: a preliminary validation study. In: Advances in peritoneal dialysis. Conference on peritoneal dialysis

13. Wakabayashi I (2016) Homocysteine levels and arterial stiffness in the general population. J Atheroscler Thromb 23(6):668-670

14. Climie RE et al (2019) Central-to-brachial blood pressure amplification in type 2 diabetes: a systematic review and meta-analysis. J Hum Hypertens 33(2):94-105

15. Yang L et al (2017) Association of central blood pressure and cardiovascular diseases in diabetic patients with hypertension. Medicine 96(42):e8286

16. Yeung SLA, Luo S, Schooling CM (2018) The impact of glycated hemoglobin (HbA1c) on cardiovascular disease risk: a Mendelian randomization study using UK Biobank. Diabetes Care 41(9):1991-1997

17. Silbernagel $G$ et al (2019) LDL triglycerides, hepatic lipase activity, and coronary artery disease: an epidemiologic and Mendelian randomization study. Atherosclerosis 282:37-44

18. Vlachopoulos C, Aznaouridis K, Stefanadis C (2010) Prediction of cardiovascular events and all-cause mortality with arterial stiffness: a systematic review and meta-analysis. J Am Coll Cardiol 55(13):1318-1327

19. Eguchi K et al (2018) High central blood pressure is associated with incident cardiovascular events in treated hypertensives: the ABC-J II Study. Hypertens Res 41(11):947-956

20. Mitchell GF et al (2010) Arterial stiffness and cardiovascular events: the Framingham Heart Study. Circulation 121(4):505

21. Avolio A, Schiffrin EL (2018) Are central hemodynamic parameters better prognostic markers than peripheral blood pressure in stroke? Artery Res 24:65-65

\section{Publisher's Note}

Springer Nature remains neutral with regard to jurisdictional claims in published maps and institutional affiliations.

\section{Submit your manuscript to a SpringerOpen ${ }^{\circ}$ journal and benefit from:}

- Convenient online submission

- Rigorous peer review

- Open access: articles freely available online

- High visibility within the field

- Retaining the copyright to your article

Submit your next manuscript at $\boldsymbol{\nabla}$ springeropen.com 